\title{
Lead acid battery recycling in Costa Rica: a case study
}

\author{
G. Esquivel-Hernández ${ }^{1}$, P. Bolaños-Ulloa ${ }^{3}$, M. Navarro-Monge ${ }^{1}$, \\ R. Alfaro-Solís ${ }^{1}$, J. P. Sibaja-Brenes ${ }^{1}$, J. C. Mora-Barrantes ${ }^{2}$ \\ \& J. Valdés-González ${ }^{1}$ \\ ${ }^{1}$ Laboratorio de Química de la Atmósfera, Escuela de Química, \\ Universidad Nacional, Costa Rica \\ ${ }^{2}$ Escuela de Química, Universidad Nacional, Costa Rica \\ ${ }^{3}$ Recuperadora Nacional de Plomo S.A., Costa Rica
}

\begin{abstract}
This work describes the production of secondary lead in a smelter located in Costa Rica. The only input of the plant is scrap automotive batteries. We describe the environmental management strategies used for waste minimization, including the waste characterization and minimization of gaseous emissions. The waste characterization included the sulphidic slag containing varying quantities of lead (total lead content and TCLP), along with the gaseous analysis $\left(\mathrm{SO}_{2}, \mathrm{TSP}\right.$ and $\mathrm{P}-\mathrm{Pb}$ ). Through process improvement, we reduced both the quantity of slag produced and the lead loss to the slag, as well as the concentrations of gas pollutants in the gaseous emissions.
\end{abstract}

Keywords: secondary lead, waste management, slag, gaseous emissions.

\section{Introduction}

Several decades ago it was recognized that all the metallurgical industries not only had to take care of the process of manufacture but also safe disposal of the pollutants generated in the form of solids, liquids or gaseous wastes [1]. Metallurgical industries produce important quantities of solid wastes such as slag, ash, sludge, dross and others, whereas the heavy and toxic metals, mainly arsenic, cadmium, chromium, nickel, lead, copper, mercury and zinc, are 
considered poisonous to the environment, The major environmental degradation is caused by copper, lead and zinc industries [1].

One of the main uses of lead around the world is the production of lead-acid batteries. In fact, $60 \%$ of the batteries sold in the entire world every year are lead-acid batteries [2]. This is one the reasons because lead-acid batteries recycling is nowadays implemented in many countries as an effective and simple way to recover this metal, where about $50 \%$ of the lead consumed worldwide is derived from recycled and reused materials [2]. In this process, batteries are broken, crushed and automatically separated into various components; in order to recover the metallic components (about 50\% weight in battery) for the smelting step. This metallic material is consisting of a mixture of lead oxides and sulfates. At the smelting step, named pyrometallurgical process, the lead compounds are reduced to metallic lead by smelting the battery paste (lead oxide, with a small amount of sulfate) with coke or other reducing agent rich in carbon and cast iron $(\mathrm{Fe})$ and sodium carbonate $\left(\mathrm{Na}_{2} \mathrm{CO}_{3}\right)$ for the removal of other metals $(\mathrm{Cu}, \mathrm{Sn}$, As, Ag, etc.) in the oxide form. This reduction process derived from the battery metallic materials leads to the formation of sulfides, named lead slag, as well to gases and particulate matter emissions. The equipment used is a rotary furnace, short or long, to minimize the amount of waste, along emissions control systems, such as baghouses for the filtration and recovery of the lead-rich particulate matter.

The slag is stored temporarily in open air deposits, where it loses its soluble components and becomes stable. For the slag to be classified as environmentally safe, a minimum aging period (about 6 months) is necessary for the slag to lixiviate under natural conditions or by washing processes, in order to lose its soluble components [2].

There is only one major organization, namely Recuperadora Nacional de Plomo S.A. (RNP), producing lead metal in Costa Rica. The RNP uses only scrap battery. The production capacity of RNP is 2200 ton per year of secondary lead, being this production exported entirely to Colombia. In this work, we report gas stack emissions, namely sulfur dioxide $\left(\mathrm{SO}_{2}\right)$, total suspended particulate matter (TSP) and particulate lead emissions (P-Pb). We have also analyzed the slag composition (total lead content) and its leaching characteristics through the toxicity characteristic leaching procedure (TCLP), in order to achieve two objectives: improve the process efficiency, namely the quantity of lead lost in the baghouse fumes and slag, but also to reduce the emissions of gas pollutants. These two objectives allowed RNP to meet consistently the Costa Rican environmental regulations and to increase the environmental process efficiency.

\section{Experimental}

The experimental approach of this work was similar to that reported by other authors [3]. However, because of the limited budget available, we decided to focus our work on tracking the losses of lead, namely the amount of lead present in the baghouse dust and stack particulate matter, along with the analysis of the slag (lead content and TCLP). We define as start point the former furnace's 
charge composition used in RNP, which was defined as the percentage of anthracite (coke), cast iron and sodium carbonate. Typically the composition of each charge was at least $79 \%$ in lead bearing materials. The optimization of the process was carried out by varying the amount of these materials in the feed in order to achieve a more efficient reduction process in the furnace, i.e. a lesser amount of lead lost during the process. RNP operates under a batch production system, where every batch requires 4 hours to be completed. For this study, we had only one furnace available.

The analyses of the baghouse fumes and the slag were done by acid digestion and atomic absorption (AA). In each case, 0.5-1.0 $\mathrm{g}$ of the solid material was homogenized and acid digested in a microwave digestion system CEM MARS 5 (CEM, USA). An atomic absorption spectrophotometer ZEEnit 700P was used for the lead quantitative analysis (Analytical Jena, Germany). The baghouse dust and slag were collected after every batch was completed. The toxicity characteristic leaching procedure (TCLP) was applied to the slags according to EPA Method 1311 [4].

The stack gas analyses were done according to the Environmental Protection Agency (EPA) stationary source emissions test methods [4]. A TESTO 350 (Testo AG, Germany) flue gas analyzer was used for the analysis of $\mathrm{SO}_{2}$ and flue gases, whereas an APEX XC-522 isokinetic sampler (Apex Instruments, USA) was used for the total suspended particulate matter (TSP) sampling. Stack gas and particulate matter sampling was carried out during the furnace operation and until every batch was completed. The lead content in the particulate matter (P$\mathrm{Pb}$ ) matter was extracted by acid digestion and analyzed by atomic absorption (AA).

\section{Results and discussion}

In order to evaluate the influence of the furnace's charge composition on the lead lost in the slag and baghouse fumes, we compared three furnace's charge compositions, which are indicated in figure 1 and figure 2 as 8-8-5, 7.4-7.4-5.3 and 5-5-3. This numbers indicate the percentage of $\mathrm{Na}_{2} \mathrm{CO}_{3}$, cast iron (Fe) and anthracite in each charge, in this order. For example, a furnace's charge named 8-8-5 was composed with $8 \% \mathrm{Na}_{2} \mathrm{CO}_{3}, 8 \% \mathrm{Fe}$ and $5 \%$ anthracite. The rest of the charge was composed of lead containing materials, formed mainly of metallic lead and lead paste (a mixture of lead oxides and lead sulphate). These four materials were mixed thoroughly and dry in an open air bunker before being introduced in the furnace.

As can be seen in figure 1 and figure 2, the furnace's charge composition plays an important role in the efficiency of the reduction process, and determines the amount of lead that is lost both in the particulate matter and in the slag. In our case, we found that a 7.4-7.4-5.3 formulation decreases the content of lead in the baghouse dust and slag. The baghouse dust composition found in our samples is similar to that reported in a previous work [3]. 


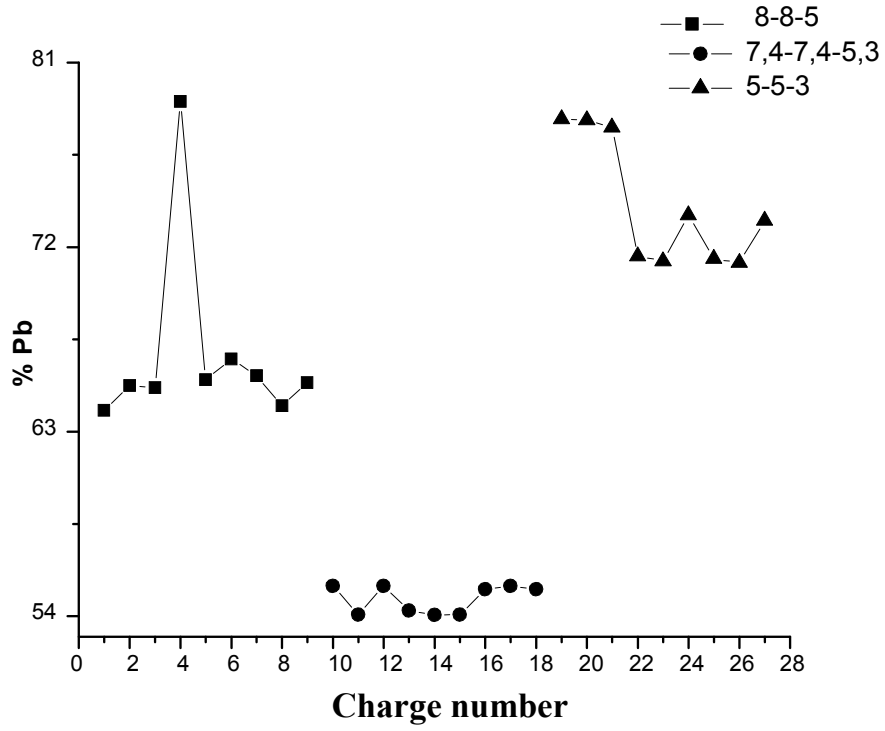

Figure 1: Variation of the percentage of lead in the baghouse dust during the furnace`s operation.

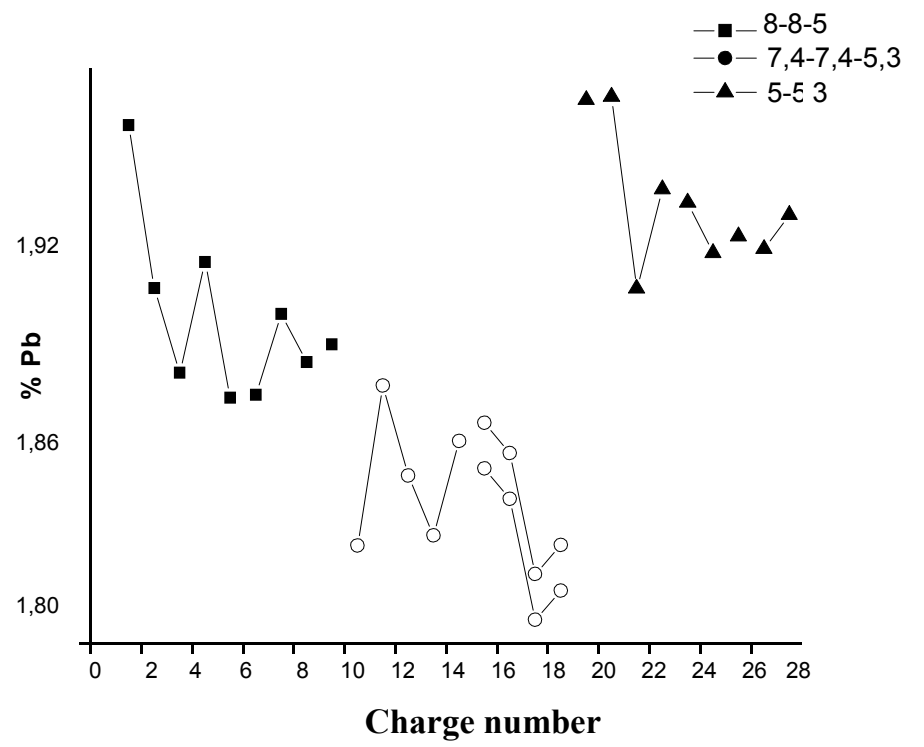

Figure 2: Variation of the percentage of lead in the slag during the furnace`s operation.

However, we found a relative steady lead content in the slag, which can be explained by the process used at RNP to recover lead. RNP uses a process called 
double smelting, where after every batch the slag is left in the furnace. At the end of the day, the furnace is charge with $\mathrm{Na}_{2} \mathrm{CO}_{3}, \mathrm{Fe}$ and anthracite, and the lead remaining in the slag is recovered. This procedure seems to reduce the content of lead in the slag, which can explained the trends observed in figure 2.

As observed in Figure 1 and 2, an important improvement in the smelting process was accomplished by changing the furnace's charge composition, which can be explained in the optimization of the Fe:S ratio fed to the furnace, along with an increase of the quantity of coke required to fulfill the reduction reaction of $\mathrm{PbSO}_{4}$ and $\mathrm{PbO}$ [3].

Regarding stack gas emissions, we found also an improvement in the quantities of total suspended particulate matter, particulate lead and sulfur dioxide emitted into the atmosphere. As observed in Figure 3, the furnace's charge composition influences the performance of the gas and particulate matter treatment system installed in RNP, which by the time this work began; it was reported to have a poor efficiency.

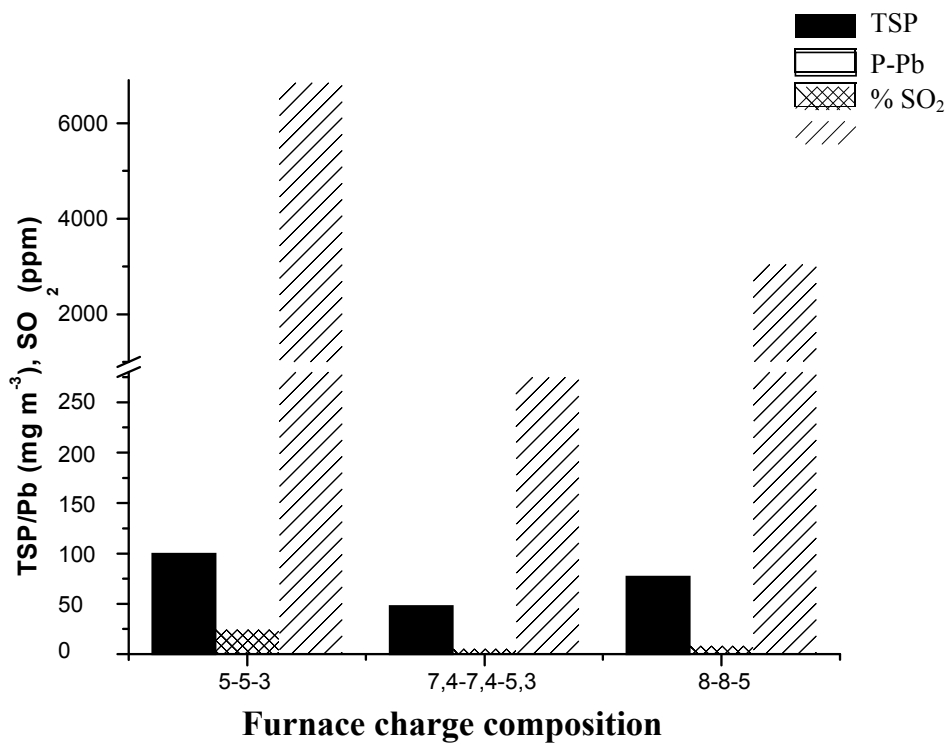

Figure 3: Average total suspended particulate matter, particulate lead and sulfur dioxide as function of furnace's charge composition.

We achieved a reduction in the gas concentration of $\mathrm{SO}_{2}$ and particulate matter emissions by changing the furnace's charge composition, which can be explained on the basis of a better reduction process of the lead present in the furnace, along with an improvement in the operation of the gas treatment system. As can be seen in Figure 3, average $\mathrm{SO}_{2}$ concentration was $275 \mathrm{ppm}$, which is a relative high value as compared to what it has been regulated previously [5]. However, the implemented changes in the process of RNP allowed us to reduce the emitted $\mathrm{SO}_{2}$ concentration in at least $95 \%$. The 
installation of a wet scrubber system could reduce even more the measured concentrations of $\mathrm{SO}_{2}$.

As this work progressed, the lack of a process control system in RNP was identified as an evident cause of the poor efficiency observed in the lead recovery process. In order to provide RNP with a simple but efficient way of controlling its process, we trained RNP staff in the use of redox titrimetric procedure, where the iron II present in the slag is oxidized to iron III by using potassium permanganate. It has been demonstrated that the amount of iron II present in the slag can be correlated with the amount of lead lost during the smelting process [6]. This means that RNP could use a simple wet chemical analysis to control its process and to optimize the furnace's charge composition if needed. As can be seen in Figure 4, it was observed a very good correlation for both parameters, which supports the use of this wet chemical analysis as a control process tool.

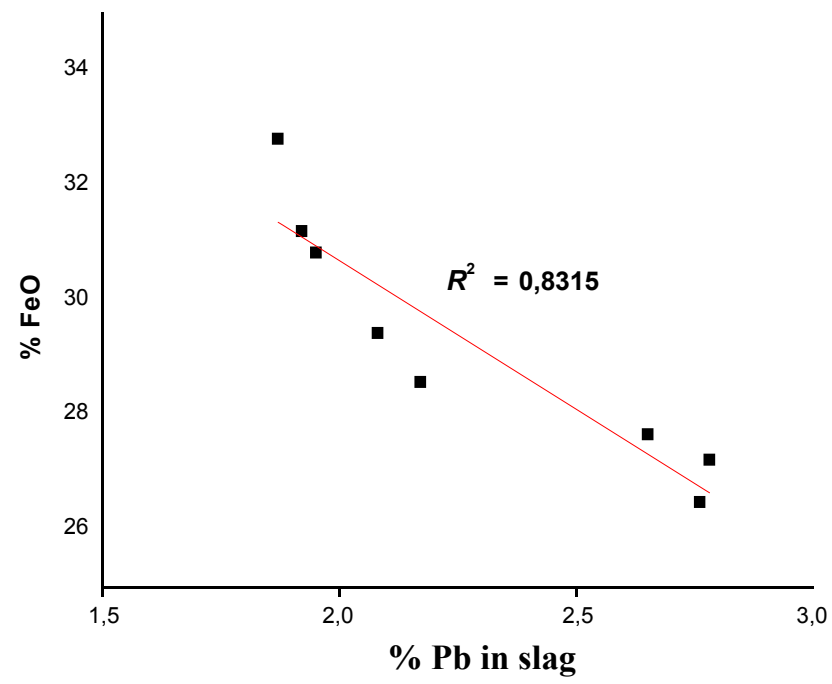

Figure 4: Percentage of iron oxide II as function of the lead content in the slag.

It has been recognized that the slag represents the largest quantity of plant waste. This material is chemically active, but diminishes in activity with time giving rise to more stable slag, called 'old slag' [3, 7]. In RNP the slag is stored in open air containers, where it oxidizes until $\mathrm{Fe}$ (II) is converted to $\mathrm{Fe}$ (III), obtaining a stable material that can be landfilled. As shown in Table 1, we found that the slag produced in RNP before the process optimization lixiviates relative high quantities of lead when was tested according the TCLP procedure. This finding could be explained on the higher slag's lead content obtained with the former charge's compositions, but also in the less efficient furnace's operation, which led to the formation of non stable slag, even after the aging process was 
carried out. As can be seen in Table 1, after the furnace's charge composition was optimized, the concentration of lead in the lixiviate was below the US EPA limit of $5 \mathrm{ppm}$, which is the same limit set by the Costa Ricans environmental regulations.

Table 1: $\quad$ Average TCLP tests in comparison to US EPA regulatory limits.

\begin{tabular}{|c|c|c|c|}
\hline Analyte & \multicolumn{2}{|c|}{ TCLP test } & \multirow{2}{*}{$\begin{array}{c}\text { US EPA } \\
\text { limit }\end{array}$} \\
\cline { 2 - 3 } & $\begin{array}{c}\text { Before process } \\
\text { optimization }\end{array}$ & $\begin{array}{c}\text { After process } \\
\text { optimization }\end{array}$ & \\
\hline $\mathrm{Pb}$ & $54,2 \mathrm{ppm}$ & $1,6 \mathrm{ppm}$ & $5 \mathrm{ppm}$ \\
\hline
\end{tabular}

\section{Conclusions}

The results obtained in this work demonstrated that the amount of lead lost both in the baghouse fumes and the slag was higher than expected because the furnace's charge composition was not optimized. A significant decrease in the lead content in the baghouse dust, as well as in the gaseous emissions was achieved and allowed RNP to reduce the related gas and particulate matter emissions. Even when the lead content in the slag was somewhat stable, it was found that the slag's stabilization process was improved when the slag generated in the furnace was obtained under a strong reduction environment, i.e. under optimized quantities of anthracite, cast iron and sodium carbonate.

The efforts made by RNP to optimize its production process are according to the project initiated in 2002 by the Basel Secretariat in Central America and the Caribbean, which seeks to develop a Regional strategy to recover and recycle used lead acid batteries (ULAB) in an environmentally sound manner that conformed to the Basel Technical Guidelines for the Environmentally Sound Management of Used Lead Acid Batteries [8].

\section{References}

[1] Agrawal, A., Sahu, K.K., and Pandey, B.D., Solid waste management in non- ferrous industries in India. Resources, Conservation and Recycling, 42, pp. 99-120, 2004.

[2] Smaniotto, A., Antunes, A., do Nascimento Filho, I., Dornelles Venquiaruto, L., de Oliveira, D., Mossi, A., Di Luccio, M., Treichel, H., and Dallago, R., Qualitative lead extraction from recycled lead-acid batteries slag. Journal of Hazardous Materials, 172, pp. 1677-1680, 2009.

[3] Lewis, A.E., Beautement, C., Prioritising objectives for waste reprocessing: a case study in secondary lead refining. Waste Management, 22, pp. 677685, 2002.

[4] United States Environmental Protection Agency (USEPA). Emissions Measurement Center, NSPS Method (40 CFR Part 60, Appendix A), Washington DC, http://www.epa.gov/ttn/emc/promgate.html 
258 Waste Management and the Environment VI

[5] IFC World Bank Group. Lead and Zinc Smelting. http://www.ifc.org/ifcext/enviro.nsf/AttachmentsByTitle/gui_leadzinc WB/ \$FIL E/leadzinc PPAH.pdf

[6] Calvo, F.A., and Ballester, A., Lead losses in the slag of reduction melting furnace. Erzmetall, 39(6), pp. 282-287, 1986.

[7] Coya, B., Marañon, E., and Sastre, H., Ecotoxicity assessment of slag generated in the process of recycling lead from waste batteries. Resources, Conservation and Recycling, 29, pp. 291-300, 2000.

[8] Araujo, M., and Wilson, B., Impact of the Regional ULAB Recycling Strategies for Central America and the Caribbean. Basel Convention Seventh Session of the Open-ended Working Group, Geneva, Switzerland, pp. 1-22, 2010 . 